\title{
Minimal incidence of neonatal/infancy onset diabetes in Italy is 1:90,000 live births
}

\author{
D. Iafusco $\cdot$ O. Massa $\cdot$ B. Pasquino $\cdot$ C. Colombo $\cdot$ L. Iughetti $\cdot$ C. Bizzarri $\cdot$ \\ C. Mammì • D. Lo Presti - T. Suprani $\cdot$ R. Schiaffini $\cdot$ Colin G. Nichols · \\ L. Russo - V. Grasso $\cdot$ F. Meschi $\cdot$ R. Bonfanti $\cdot$ S. Brescianini $\cdot$ F. Barbetti $\cdot$ \\ The Early Diabetes Study Group of ISPED
}

Received: 8 August 2011/Accepted: 25 August 2011/Published online: 28 September 2011

(c) The Author(s) 2011. This article is published with open access at Springerlink.com

\begin{abstract}
Until early 2000, permanent and transient neonatal diabetes mellitus (NDM), defined as diabetes with onset within 6 weeks from birth that requires insulin therapy for at least 2 weeks, were considered exceedingly rare conditions, with a global incidence of 1:500,000-1:400,000 live births. The new definition of NDM recently adopted, that includes patients with diabetes onset within 6 months of age, has prompted studies that have set the incidence of the permanent form alone between 1:210,000 and 1:260,000 live births. Aim of the present work was to ascertain the incidence of NDM (i.e. permanent + transient form) in Italy for years 2005-2010. Patients referred to the Italian reference laboratory for NDM between years 2005 and 2010 and screened for mutations in common NDM genes
\end{abstract}

D. Iafusco

Department of Pediatrics, Second University of Naples,

Naples, Italy

O. Massa · C. Colombo · L. Russo · F. Barbetti

Laboratory of Mendelian Diabetes, Bambino Gesù Children's

Hospital, IRCCS, Rome, Italy

B. Pasquino

Department of Pediatrics, Regional Hospital, Bolzano, Italy

L. Iughetti

Department of Pediatrics, University of Modena and Reggio

Emilia, Modena, Italy

C. Bizzarri · R. Schiaffini

Endocrine Unit, Bambino Gesù Children's Hospital,

IRCCS, Rome, Italy

C. Mammì

Medical Genetics Unit, Bianchi Melacrino Morelli Hospital,

Reggio Calabria, Italy

D. Lo Presti

Department of Pediatrics, University of Catania, Catania, Italy
(KCNJ11, ABCC8, and INS) and for uniparental isodisomy of chromosome 6 (UDP6) were reviewed. A questionnaire aimed at identifying NDM cases investigated in other laboratories was sent to 54 Italian reference centers for pediatric diabetes. Twenty-seven patients with NDM born between 2005 and 2010 were referred to the reference laboratory. In this group, a mutation of either KCNJ11, $A B C C 8$ or INS was found in 18 patients, and a case with UDP6 was identified. Questionnaires revealed 4 additional cases with transient neonatal diabetes due to UDP6. Incidence of NDM was calculated at 1:90,000 (CI: 1:63,000-1:132,000) live births. Thus, with the definition currently in use, about 6 new cases with NDM are expected to be born in Italy each year.

\section{T. Suprani}

Department of Pediatrics, Maurizio Bufalini Hospital,

Cesena, Italy

\section{G. Nichols}

Department of Cell Biology and Physiology, Washington

University School of Medicine, St Louis, Missouri, USA

V. Grasso

Department of Laboratory Medicine, Tor Vergata University Hospital, Rome, Italy

F. Meschi · R. Bonfanti

Department of Pediatrics, H S Raffaele Hospital and Scientific Institute, Milan, Italy

S. Brescianini

Department of Epidemiology, Istituto Superiore di Sanità,

Rome, Italy

F. Barbetti ( $\square)$

Department of Internal Medicine, University of Tor Vergata,

Via Montpellier 1, 00134 Rome, Italy

e-mail: Fabrizio.Barbetti@uniroma2.it 
Keywords Neonatal diabetes mellitus - Permanent neonatal diabetes mellitus - Transient neonatal diabetes mellitus · Incidence

$\begin{array}{ll}\text { Abbreviations } \\ \text { ISPED } & \begin{array}{l}\text { Italian society for pediatric endocrinology and } \\ \text { diabetes }\end{array} \\ \text { MDI } & \begin{array}{l}\text { Monogenic diabetes of infancy } \\ \text { NDM }\end{array} \\ \text { Neonatal diabetes mellitus } \\ \text { TNDM } & \text { Transient neonatal diabetes mellitus } \\ \text { PNDM } & \text { Permanent neonatal diabetes mellitus } \\ \text { UPD6 } & \text { Uniparental isodisomy of chromosome } 6\end{array}$

\section{Background}

Neonatal/infancy onset diabetes mellitus (NDM) is a monogenic form of diabetes with onset within 6 months from birth. Two distinct types of NDM have been recognized: permanent (PNDM) and transient (TNDM) [1, 2]. In patients with TNDM, remission of hyperglycemia usually occurs within 3-6 months from diagnosis [1, 2]. In addition, in about $50 \%$ of individuals with TNDM, diabetes may relapse at adolescence.

Paternal isodisomy of chromosome 6 (UDP6), paternal duplication, or loss of maternal methylation of chromosome 6q24 have been reported as the most frequent causes of TNDM ( $>65 \%$ of cases) [1], followed by activating mutations in $A B C C 8$ and $K C N J 11$ genes, which encode the two subunits of the ATP-sensitive potassium $\left(\mathrm{K}_{\mathrm{ATP}}\right)$ channel of pancreatic b-cell [1]. Differently, mutations of $\mathrm{K}_{\mathrm{ATP}}$ channel and INS genes are found in most patients with PNDM (also termed monogenic diabetes of infancy, MDI) [3, 4]. Many other genes are involved in exceedingly rare, recessive subtypes of PNDM/MDI [1, 2].

Until 2002, NDM (i.e. PNDM + TNDM) was considered very rare with an incidence of 1:400,000-1:500,000 live births [5-7]. At that time the cut-off in use to define NDM was hyperglycemia with onset within 6 postnatal weeks in patients born at term and treated with insulin for at least 2 weeks [5]. In 2002, a study from our group suggested that patients with diabetes onset in the first 6 months of life do not show the typical laboratory features of type 1 diabetes [8]. The subsequent discovery of activating mutations of KCNJ11 gene in individuals with diabetes onset within 6 months from birth confirmed those findings [9, 10]. Recently, the incidence of the permanent form alone has been calculated between 1:210,000 live births of Italy and Slovakia $[3,11]$ and 1:260,000 of other European countries [12]. These higher incidence rates can be attributed to the adoption of the new limit of 6 months of age for diagnosing neonatal/infancy onset diabetes and are not comparable to the increased incidence observed for type 1 diabetes, even of very early onset (i.e. $0-4$ years) [13].

With the present study, we wanted to assess the minimal incidence of NDM (i.e. PNDM/MDI + TNDM) in Italy of a 6-year period (2005-2010).

\section{Research design and methods}

We reviewed cases with NDM born between 2005 and 2010 and referred to the laboratory of Mendelian Diabetes in Rome, the reference laboratory for NDM of the Italian Society of Pediatric Endocrinology and Diabetology (ISPED). From this database, we included only cases with the following features: (1) diabetes onset within 6 months from birth and (2) hyperglycemia treated with insulin for at least 2 weeks. Two exceptions were represented by cases positive to the molecular genetic screening, but with insulin therapy of shorter duration (10 and 12 days, respectively). In addition, to ascertain whether any patient with NDM could have been referred to other laboratories, we sent a questionnaire to 54 pediatric diabetes clinics that are the referral centers for the diagnosis and treatment of diabetes in childhood in Italy. These 54 clinics are scattered throughout the country and provide a rather complete coverage. Cases identified through the questionnaire whose medical records could not be revised were not included in the study.

Incidence rates per 100,000 live births were computed combining cases from the laboratory of Mendelian diabetes and from the questionnaire.

\section{Results}

Twenty-seven cases (16 with PNDM/MDI and 11 with TNDM) born between 2005 and 2010 and referred to the laboratory of Mendelian Diabetes matched the clinical criteria we used to define NDM. In patients with NDM, we identified a causative mutation in 11 cases with permanent diabetes (7 KCNJI1 and 4 INS) $(3,4$; and the frequent $K C N J 11 / \mathrm{R} 201 \mathrm{H}$ mutation in a patient born in September 2010) and 7 with transient diabetes (mutations: $A B C C 8 /$ S459R, ABCC8/R1380C, ABCC8/V1523M， KCNJ11/ R50Q (twice), KCNJ11/E229K, and 1 case with UDP6). Transient neonatal diabetes mutations $K C N J 11 / \mathrm{R} 50 \mathrm{H}$, $K C N J 11 / \mathrm{E} 229 \mathrm{~K}$, and $A B C C 8 / \mathrm{R} 1380 \mathrm{C}$ have been previously reported [14], while $A B C C 8$ mutations in same residue as ours, but with different amino acid change such as $\mathrm{V} 1523 \mathrm{~A} / \mathrm{L}$ have been described associated with permanent 
neonatal diabetes [14]. Mutation $A B C C 8 / \mathrm{S} 459 \mathrm{R}$ appears to be novel.

Fifty centers out of 54 replied to the questionnaire (92\%). Data collected revealed that 4 additional patients born between 2005 and 2010 and unknown to us had received a diagnosis TNDM; defects of chromosome 6 were identified in all of them. In two of the latter cases, insulin therapy duration was 10 and 12 days, respectively.

Minimal incidence of NDM (i.e. PNDM/MDI + TNDM) in Italy for years 2005-2010 was calculated at 1:90,000 (CI: $1: 63,000-1: 132,000)$.

\section{Discussion/conclusions}

Cases with the transient form of neonatal/infancy onset diabetes mellitus may be lost at follow-up, during the period of remission, while cases with the permanent form are obviously less prone to this problem. For this reason, we decided to investigate, to the purpose of epidemiological assessment, a period of time reasonably long, but also as close as possible to the present days and posterior to the discovery of the main gene causing NDM, i.e. KCNJ11 [9]. In addition, we also distributed a questionnaire for data collection to all Italian clinics for pediatric diabetes, in order to identify cases with NDM that could have not been referred to the reference laboratory in Rome. Questionnaire's results showed that this was in fact the case and four patients with TNDM born between 2005 and 2010 had been diagnosed with UDP6 in other laboratories. Nevertheless, in patients with transient diabetes, we observedin contrast with the literature [1] — a higher prevalence of $\mathrm{K}_{\mathrm{ATP}}$ mutations compared to defects of chromosome 6 $\left(\mathrm{K}_{\mathrm{ATP}}=6 / 15\right.$ vs. UDP6 $\left.=5 / 15\right)$. Therefore, it is still possible that we could have missed some TNDM cases associated with UDP6, maybe referred to the 4 centers that have not sent back the questionnaire. In addition, the short duration of insulin therapy observed in two cases with UDP6 should alert about the thin line separating "true" cases with transient neonatal diabetes (i.e. cases by definition treated with insulin for at least 2 weeks) from patients with mild hyperglycemia due to other genetic causes and treated with insulin for short period [15].

A similar incidence of NDM of 1:89,000 has been recently reported from Germany [16]. However, though incidence rates were almost identical, we noticed three major differences with our study: (1) patients with TNDM represented only $10 \%$ of the total, (2) type 1 diabetes autoantibodies were present in seven patients with permanent diabetes, and (3) a mutation was found in only $30 \%$ of cases. In our study, patients with PNDM and TNDM accounted for about $50 \%$ of cases each, a mutation was found in $74 \%$ of patients (23/31), and all cases were negative for type 1 autoantibodies. We can not offer at this time any explanation for all the discrepancies observed between the two studies.

In conclusion, the present study and our previous results [3] indicate that a genetic diagnosis can be reached in most patients with NDM and confers robustness to our epidemiological data. At an incidence rate of 1:90,000 live births, about six individuals presenting with neonatal diabetes are expected to be born in Italy each year.

Acknowledgments This work has been supported by the grant "Molecular mechanisms in the pathogenesis of type 2 diabetes mellitus and its cardiovascular complications" by Fondazione Roma and by Transnational European research grant on Rare Diseases (ERANET 09 RARE 005), both to F.B.

Open Access This article is distributed under the terms of the Creative Commons Attribution Noncommercial License which permits any noncommercial use, distribution, and reproduction in any medium, provided the original author(s) and source are credited.

\section{References}

1. Aguilar-Bryan L, Bryan J (2008) Neonatal diabetes mellitus. Endocr Rev 29:265-291

2. Murphy R, Ellard S, Hattersley AT (2008) Clinical implications of a molecular genetic classification of monogenic $\beta$-cell diabetes. Nat Clin Pract End Met 4:200-213

3. Russo L, Iafusco D, Brescianini S, Nocerino V, Bizzarri C, Toni S, Cerutti F, Monciotti C, Pesavento R, Iughetti L, Bernardini L, Bonfanti R, Gargantini L, Vanelli M, Aguilar-Bryan L, Stazi A, Grasso V, Colombo C, Barbetti F, The Early Diabetes Study Group of ISPED (2011) Permanent diabetes during the first year of life: multiple gene screening in 54 patients. Diabetologia 54:1693-1701

4. Colombo C, Porzio O, Liu M, Massa O, Vasta M, Salardi S, Beccaria L, Monciotti C, Toni S, Pedersen O, Hansen T, Federici L, Pesavento R, Cadario F, Federici G, Ghirri P, Arvan P, Iafusco D, Barbetti F, The Early onset diabetes Study Group of the Italian Society of Pediatric Endocrinology, Diabetes (SIEDP) (2008) Seven mutations in the human insulin gene linked to permanent neonatal/infancy-onset diabetes mellitus. J Clin Invest 118:21482156

5. von Mühlendahl KE, Herkenhoff H (1995) Long-term course of neonatal diabetes. N Engl J Med 333:704-708

6. Shield JPH, Gardner RJ, Wadsworth EJK, Whiteford ML, James RS, Robinson DO, Baum JD, Temple IK (1997) Aetiopathology and genetic basis of neonatal diabetes. Arch Dis Child 76: F39-F42

7. Metz C, Cavé H, Bertrand AM, Deffert C, Gueguen-Giroux B, Czernichow P, Polak M (2002) Neonatal diabetes mellitus: chromosomal analysis in transient and permanent cases. J Pediatr 141:483-489

8. Iafusco D, Stazi MA, Cotichini R, Cotellessa M, Martinucci ME, Mazzella M, Cherubini V, Barbetti F, Martinetti M, Cerutti F, Prisco F, The Early Onset Diabetes Study Group of the Italian Society of Paediatric Endocrinology, Diabetology (2002) Permanent diabetes mellitus in the first year of life. Diabetologia 45:798-804

9. Gloyn AL, Pearson ER, Antcliff JF, Proks P, Bruining GJ, Slingerland AS, Howard N, Srinivasan S, Silva JMCL, Molnes J, 
Edghill EL, Frayling TM, Temple IK, Mackay D, Shiled JPH, Sumnik Z, van Rhijn A, Wales JKH, Clark P, Gorman S, Aisenberg J, Ellard S, Njolstad PR, Ashcroft FM, Hattersley AT (2004) Activating mutations in the gene encoding the ATP-sensitive potassium channel subunit Kir6.2 gene and permanent neonatal diabetes. N Engl J Med 350:1838-1849

10. Massa O, Iafusco D, D'Amato E, Gloyn AL, Hattersley AT, Pasquino B, Tonini G, Dammacco F, Zanette G, Meschi F, Porzio $\mathrm{O}$, Bottazzo GF, Crinò A, Lorini R, Cerutti F, Vanelli M, Barbetti F, The Early Onset Diabetes Study Group of the Italian Society of Pediatric Endocrinology, Diabetology (2005) KCNJ11 activating mutations in Italian patients with permanent neonatal diabetes. Hum Mutat 25:22-27

11. Stanik J, Gasperikova D, Paskova M, Barak L, Javorkova J, Jancova E, Cljakova M, Hlava P, Michalek J, Flanagan SE, Pearson E, Hattersley AT, Ellard S, Klimes I (2007) Prevalence of permanent neonatal diabetes in Slovakia and successful replacement of insulin with sulfonylurea therapy in $\mathrm{KCNJ} 11$ and $\mathrm{ABCC} 8$ mutation carriers. J Clin Endocrinol Metab 92:1276-1282

12. Slingerland AS, Shields BM, Flanagan SE, Bruining GJ, Noordam K, Gach A, Mlynarski W, Malecki MT, Hattersley AT, Ellard S
(2009) Referral rates for diagnostic testing support an incidence of permanent neonatal diabetes in three European countries of at least 1 in 260,000 live births. Diabetologia 52:1683-1685

13. Jarosz-Chobot P, Deja G, Polanska J (2010) Epidemiology of type 1 diabetes among Silesian children aged 0-14 years, 1989-2005. Acta Diabetol 47:29-33

14. Flanagan SE, Clauin S, Bellané-Chantelot C, de Lonlay P, Harries LW, Gloyn AL, Ellard S (2009) Update of mutations in the genes encoding the pancreatic beta-cell KATP channel subunits Kir6.2 (KCNJ11) and sulfonylurea receptor 1 (ABCC8) in diabetes mellitus and hyperinsulinism. Hum Mutat 30:170-180

15. Prisco F, Iafusco D, Franzese A, Sulli N, Barbetti F (2000) MODY 2 presenting as neonatal hyperglycemia: a need to reshape the definition of "neonatal diabetes"? Diabetologia 43:1331-1332

16. Grulich-Henn J, Wagner V, Thont A, Schober E, Marg W, Kapellen TM, Haberland H, Raile K, Ellard S, Flanagan SE, Hattersley AT, Holl RW (2010) Entities and frequency of neonatal diabetes: data from the diabetes documentation and quality management system (DPV). Diabetic Med 27:709-712 